\title{
Nitrogen-doped carbon foams synthesized from banana peel and zinc complex template for adsorption of $\mathrm{CO}_{2}$,
}

\section{$\mathrm{CH}_{4}$ and $\mathrm{N}_{2}$}

Arash Arami-Niya, Thomas E. Rufford* and Zhonghua Zhu

School of Chemical Engineering, The University of Queensland, St Lucia 4072 Australia

*Corresponding author: t.rufford@uq.edu.au

Keywords Carbon foam, biomass wastes, nitrogen doping, gas separation, $\mathrm{CO}_{2}$ capture.

\begin{abstract}
We report nitrogen-doped and activated carbon foams with large specific surface areas prepared from banana peels using a self-template method with zinc nitrate, 2-aminophenol-and furfural involved. Importantly, for development of these carbons foams for adsorption applications, we have extended the methodology of using the zinc complex template to investigate the effects of carbonization temperature, post-carbonization $\mathrm{CO}_{2}$ activation and the $\mathrm{N}$-content of the carbon foam on adsorption capacities for $\mathrm{CO}_{2}, \mathrm{CH}_{4}$ and $\mathrm{N}_{2}$. The carbon foams produced contain up to $6.0 \%$ wt nitrogen, and feature cellular macroporous structures with BET specific surface areas up to $1426 \mathrm{~m}^{2} \cdot \mathrm{g}^{-1}$. The potential of the carbon foams for $\mathrm{CO}_{2} / \mathrm{N}_{2}, \mathrm{CO}_{2} / \mathrm{CH}_{4}$ and $\mathrm{CH}_{4} / \mathrm{N}_{2}$ separations was evaluated by measurement of pure fluid adsorption capacities using a gravimetric adsorption
\end{abstract}


apparatus. The adsorption capacities at a maximum pressure of $4000 \mathrm{kPa}$ and $298 \mathrm{~K}$ were $\mathrm{CO}_{2}$ $9.21 \mathrm{mmol.g}{ }^{-1}, \mathrm{CH}_{4} 5.29 \mathrm{mmol.g}{ }^{-1}$ and $\mathrm{N}_{2} 3.29 \mathrm{mmol.g} \mathrm{g}^{-1}$.

\section{Introduction}

Carbon foams with high void volumes, hierarchical porous structures, low bulk density, and good thermal and electrical conductivity have been reported for a range of significant applications including catalyst supports, energy storage electrodes, insulation and adsorption applications 2, 3 . Carbon foams can be prepared from coal tar pitch and petroleum pitch 4, 5 , polymeric precursors ${ }^{6}$ or renewable biomass-based precursors such as sucrose ${ }^{7}$ and banana peel

1. Renewable biomass materials for carbon foams may offer long-term environmental and economic advantages to fossil-fuel sources such as pitch, plus biomass materials can provide interesting natural macroporous structures that can be utilised to create novel foam properties.

Banana peel (BP) is an agricultural waste available in large volumes as bananas are a very popular and nutritionally important fruit for a wide population of the world - the global production of bananas is more than 100 million tonnes annually ${ }^{8}$. Our collective appetite for bananas generates a large volume of waste banana peels as the peel typically represents 30 40- $\%$ of the banana's weight 9,10 and, as an alternative to disposal of banana peels from industrial food processing plants to landfills, the banana peel has potential for utilisation in biogas generation ${ }^{11}$, a source of aromatic compounds ${ }^{10}$ and activated carbon adsorbents ${ }^{12,13}$. Banana peels contain a diverse mix of biopolymers including pectin, hemicellulose, cellulose, and lignin 9,14 . Of particular relevance to our current work on carbon foams are the gel-forming properties of BP-pectins ${ }^{9}$ and the polar surface functional groups on various BP compounds, 
which can act as sites for metal ion complexation (often cited for use in heavy metal ion $\left.\operatorname{adsorption}^{15,16}\right)$.

Lv et al. ${ }^{1}$ utilised both BP's gel-forming properties and metal-complexation sites to adsorb phenolic resin-precursors to produce self-templated hierarchical carbon foams for supercapacitor electrodes. In this procedure, the introduction of 2-aminophenol to the carbon provides nitrogencontaining functional groups on the carbon foam that may present attractive properties for supercapacitor electrodes (as evaluated by $\mathrm{Lv}$ et al. ${ }^{1}$ ) and enhanced $\mathrm{CO}_{2}$ adsorption. In this

study, we extend the self-templated carbon foam methodology of Lv et al. ${ }^{1}$, and others ${ }^{17,}{ }^{18}$ by switching the argon gas to $\mathrm{CO}_{2}$ at the carbonization temperature, and the effects of carbonization temperature, post-carbonization $\mathrm{CO}_{2}$ activation and the $\mathrm{N}$-content of the carbon foam on adsorption capacities for $\mathrm{CO}_{2}, \mathrm{CH}_{4}$ and $\mathrm{N}_{2}$ have been comprehensively investigated.

\section{Experimental methods}

\subsection{Materials}

Queensland-grown yellow Cavendish bananas (Musa acuminate) were purchased from a local supermarket in Brisbane. After the first author ate the fruit, the banana peels (BP) were washed in distilled water, dried in air overnight and sliced into small pieces. Reagent grade zinc nitrate hexahydrate $\left(\mathrm{Zn}\left(\mathrm{NO}_{3}\right)_{2} \cdot 6 \mathrm{H}_{2} \mathrm{O}\right)$, furfural $\left(\mathrm{C}_{5} \mathrm{H}_{4} \mathrm{O}_{2}\right)$ and 2-aminophenol $\left(\mathrm{C}_{6} \mathrm{H}_{7} \mathrm{NO}\right)$ were used without further purification. The purities of gases used in this work, as stated by the supplier Coregas Australia, were $99.999 \%$ for helium, argon and nitrogen, and $99.995 \%$ for carbon dioxide and methane. 


\subsection{Preparation of nitrogen-doped carbon foams}

The procedure to prepare carbon foams was based on the self-template method proposed by Lv et al. ${ }^{1}$ using zinc ions coordinated with carboxylic and hydroxyl groups on the BP's pore surfaces. The key process steps in this procedure, as summarised in Fig. 1, were (1) The BP particles were soaked in 2 mol. $\mathrm{L}^{-1}$ zinc nitrate solution at $343 \mathrm{~K}$ in a closed vessel for 7 days to form zinc complexes. (2) The reaction vessel was opened and the excess water was evaporated over 14 days at $333 \mathrm{~K}$ to obtain brown zinc complexes. (3) The zinc complexes were soaked in a mixture of furfural and 2-aminophenol at $343 \mathrm{~K}$ for 7 days. This step produces a slurry of banana peel zinc complexes impregnated with a 2-aminophenol-furfural resin, which subsequently provides a N-rich carbon source during pyrolysis. (4) $7 \mathrm{~g}$ of the slurry was pressed by hand into a cylindrical quartz crucible $(2.54 \mathrm{~cm}$ diameter $\times 2.54 \mathrm{~cm}$ height $)$, dried at $393 \mathrm{~K}$ overnight and carbonized in a horizontal tube furnace at temperatures in the range of $(1023-1273) \mathrm{K}$ for carbonisation times of 1 to $11 \mathrm{hrs}$. In addition, we extended Lv et al.'s procedures ${ }^{1}$ to produce a set of $\mathrm{CO}_{2}$ activated carbon foams by switching the gas flow from argon to $\mathrm{CO}_{2}$ once the carbonisation temperature had been reached. The heating rate in all experiments was $10 \mathrm{~K} \cdot \mathrm{min}^{-1}$. Carbons produced from the banana peel zinc complexes are labelled as chemically-modified banana foams CBF-T-FF-t, where $\mathrm{T}=[1023-1273] \mathrm{K}, \mathrm{FF}$ is the gas atmosphere and $\mathrm{t}$ the duration of the carbonisation step.

As a comparison, we also prepared carbons by direct pyrolysis of the sliced BP in argon at $873 \mathrm{~K}$ to produce BP-char (heating rate $=10 \mathrm{~K} \mathrm{~min}^{-1}$; hold time $=1 \mathrm{hr}$ ) and by $\mathrm{CO}_{2}$ activation of this char to produce activated $\mathrm{BP}$ carbons (BPAC). The $\mathrm{CO}_{2}$ activation was performed after the char had cooled in argon, and then the gas was switched to $50 \mathrm{~mL} \cdot \mathrm{min}^{-1} \mathrm{CO}_{2}$ and the furnace 
temperature increased again at $10 \mathrm{~K} \mathrm{~min}^{-1}$ to $1023 \mathrm{~K}$ for 1 or 3 hours. These samples were labelled BPAC followed by the activation temperature, gas type and activation duration.

The yield of each carbon product in the pyrolysis or pyrolysis plus carbonization steps was calculated as:

$$
\operatorname{Yield}(\%)=\left(\frac{W_{f}}{W_{i}}\right) \times 100
$$

where $W_{i}$ and $W_{f}$ are the dry weight (g) of feed for each process (BP, BP char or impregnated $\mathrm{BP}$ ) and dry weight (g) of products (bio-char, BPACs or CBFs), respectively.

\subsection{Characterizations}

The carbons were characterized by scanning electron microscopy (SEM, JEOL JSM-6100), thermogravimetric analysis (TGA, Perkin Elmer STA 6000) and X-ray photoelectron spectroscopy (XPS, Kratos Axis ULTRA X-ray photoelectron spectrometer using a monochromated Al $\mathrm{K} \alpha(1486.6 \mathrm{eV})$ excitation source). The quantitative analysis of XPS data was performed with CasaXPS software after Shirley background subtraction. Bulk concentrations of $\mathrm{C}, \mathrm{H}$ and $\mathrm{N}$ were determined with an Elemental Analyzer (FlashEA1112 series), and the $\mathrm{O}$ concentrations were assumed to be the residual between $100 \%$ and the sum of $\mathrm{C}, \mathrm{H}$ and $\mathrm{N}$ concentrations.

Pore textural properties of the carbon foams were characterised by mercury intrusion porosimetry (MIP) measured at pressure of $(20$ - 414000) kPa (Micromeritics PoreSizer 9320) and sorption analyses with $\mathrm{CO}_{2}$ at $273 \mathrm{~K}$ and $303 \mathrm{~K}$ as well as $\mathrm{N}_{2}$ at $77 \mathrm{~K}$ (Micromeritics TriStar II 3020). Samples were degassed at $473 \mathrm{~K}$ and a pressure of $10^{-5}$ torr for $24 \mathrm{hr}$ prior to $\mathrm{CO}_{2}$ and $\mathrm{N}_{2}$ sorption measurements. Specific surface areas $\left(\mathrm{S}_{\mathrm{BET}}\right)$ were calculated by the Brunauer- 
Emmett-Teller method at the relative pressures in the range of $\mathrm{P} / \mathrm{P}_{0}=0.05-0.30$; total pore volumes were estimated at $\mathrm{P} / \mathrm{P}_{0}=0.98$; and volumes of micropores were calculated from both the $77 \mathrm{~K} \mathrm{~N}_{2}$ and $273 \mathrm{~K} \mathrm{CO}_{2}$ isotherms using the Dubinin-Astakhov (D-A) equation. ${ }^{1920}$ The micropore surface area was calculated using Dubinin-Radushkevich (D-R) equation on the $\mathrm{CO}_{2}$ adsorption data at $273 \mathrm{~K}$. The pore size distributions (PSD) were determined using a density functional theory model (DFT) algorithm for carbon slit pores supplied with the Micromeritics instrument.

\subsection{Gravimetric adsorption equilibria measurement}

Adsorption isotherms of pure fluids $\mathrm{CO}_{2}, \mathrm{CH}_{4}$, and $\mathrm{N}_{2}$ on carbons were measured at $(298,313$ and 323) $\mathrm{K}$ and pressures up to $4000 \mathrm{kPa}$ using a BELSORP-BG instrument (BEL Japan) equipped with a RUBOTHERM magnetic floating balance. Prior to adsorption measurements the carbon foam was degassed in-situ at $473 \mathrm{~K}$ for $24 \mathrm{hrs}$. We have previously described elsewhere the operation of this apparatus to measure adsorption on carbon materials ${ }^{19}$, so we only include here in the supporting information a brief description of the BELSORP-BG measurement procedures.

\section{Results and discussions}

\subsection{Preparation of chemically modified banana peel foam monoliths}

The SEM images in Fig. 2 show the morphology of the banana peel with open cell structures that are approximately $5-20 \mu \mathrm{m}$ wide and coated in biopolymers. The total nitrogen concentration of the raw BP determined by CHNS Elemental Analyser was $1.9 \%$ wt (Table 1), which is comparable to the BP nitrogen concentrations reported in other studies ${ }^{14}$. Proximate analysis of the raw BP by thermal gravimetric analysis obtained $67.7 \%$ wt volatiles, $24.2 \%$ wt fixed carbon 
and $8.2 \%$ wt ash. The dried (samples were dried at $473 \mathrm{~K}$ under nitrogen) raw BP's residual mass after the TGA measurement shown in Fig. 3 is consistent with the yield of $38.8 \%$ wt BPchar produced by pyrolysis of raw BP in the tube furnace (Table 1).

The TGA weight loss curve in Fig. 3 of the banana peel treated with zinc nitrate and impregnated with the furfural + 2-aminophenol resin (dry basis) shows that the BPC composite has a greater thermal stability than the raw BP at temperatures in the range (500 -773 K); this BPC weight loss curve is consistent with the decomposition of aminophenol-furfural resins reported in the literature. For example, Patel et al. ${ }^{20}$ report aminophenol-furfural resins will soften at temperatures above $473 \mathrm{~K}$ and then harden at temperatures from $703-843 \mathrm{~K}$ due to devolatilization of the resin and BP polymers. The BPC weight loss observed in Fig. 3 at temperature above $1100 \mathrm{~K}$ includes the evaporation of zinc via reduction of $\mathrm{ZnO}$ (derived from the zinc nitrate) to metallic zinc ${ }^{21,22}$. The EDX analysis of BPC and carbon foams CBF-1023Ar-3h and CBF-1273-Ar-3h (see Fig. S2) confirms the loss of zinc from the composite after pyrolysis at $1273 \mathrm{~K}$. Table 1 shows the yields of CBFs produced in argon ranged from $65.7 \%$ wt to $23.6 \% \mathrm{wt}$; the yield decreased at higher temperatures and longer carbonisation time.

An aim of this study was to produce monolithic carbon foams with a mechanically stable, open cellular structure and the chemically-modified banana foam synthesis method successfully produced monoliths of CBF, as summarised in Table 1. The inset photograph for CBFs in Fig. 1 shows a typical example of a CBF monolith in the shape of the crucible mould. In contrast, BPAC-1023- $\mathrm{CO}_{2}-1 \mathrm{~h}$ produced by a more conventional carbonisation and $\mathrm{CO}_{2}$ activation process was a loose agglomeration of granules that was easily crumbled by hand, thus not as strong and uniform as the CBFs. The SEM images of CBF-1273-Ar-3h in Fig. 4a-c show a highly porous 
foam-like open cell structure with typical carbon foam features of ligaments and walls ${ }^{23,}{ }^{24}$. Clearly, the texture of the CBF sample is different to the texture of the BPAC- $1023-\mathrm{CO}_{2}-1 \mathrm{~h}$ produced by $\mathrm{CO}_{2}$ activation of $\mathrm{BP}$ (Fig. 4g-i). Mercury intrusion porosimetry (Fig. 5) shows a broad distribution of macroporous channels in CBF-1273-Ar-3h, the largest channels are approximately $80 \mu \mathrm{m}$ wide. Table 2 provides a summary of the microporous textural properties of the CBFs and these results are discussed in details in later sections.

The $\mathrm{CO}_{2}$ activation of $\mathrm{BP}$ alone does not produce the carbon foam structure, we can infer that the porous structure developed in the CBF results partly from the devolitisation and polymerisation of furfural-aminophenol resin. There are three key stages in such a bubble growth foaming process, as has been described by Beecham et al. ${ }^{25}$ : firstly, the resin melts around $473 \mathrm{~K}$, secondly as the temperature increases further light hydrocarbons such as unreacted furfural evolve from the resin, and thirdly polymerisation of the resin leads to additional evolution of gas products and increase in the viscosity of the resin. Finally, at temperatures between $703-843 \mathrm{~K}$ the molten resin has reacted to such a degree that the resin solidifies. In the presence of the BPzinc nitrate complex, the biopolymers of the $\mathrm{BP}$ which are mostly released from raw $\mathrm{BP}$ at temperatures below $673 \mathrm{~K}$ (Fig. 3) may provide additional gas for bubble formation and growth in the resin phase.

The bulk nitrogen concentration of CBF-1023-Ar-3h was 6.0\%wt (Table 1), 2.6 times the nitrogen content of the activated carbon BPAC-1023- $-\mathrm{CO}_{2}-1 \mathrm{~h}(2.3 \% \mathrm{wt} \mathrm{N})$. The source of the additional $\mathrm{N}$ in the chemically-modified $\mathrm{CBF}$ is the 2-aminophenol $\left(\mathrm{C}_{6} \mathrm{H}_{7} \mathrm{NO}\right.$ contains $12.83 \% \mathrm{wt} \mathrm{N}$ ) and the intermediate composite BPC contained $8.0 \%$ wt N. Characterisation of the N-containing groups in BPC by XPS (as shown in Fig. 6a and Table 3) confirms the presence of 
amine groups $(\mathrm{N}-1 \text { at binding energy (BE) of } 399.4 \pm 0.1 \mathrm{eV})^{26-28}$ and amides $(\mathrm{N}-2$ at $\mathrm{BE}=400.5 \pm 0.1 \mathrm{eV}$ ) from the 2-aminophenol-furfural $\operatorname{resin}^{20}$. The N-3 group detected in the XPS of $\mathrm{BPC}$ around $\mathrm{BE}=407.3 \pm 0.1 \mathrm{eV}$ may be attributed to unreacted nitrate salts from the zinc nitrate reagent. ${ }^{26-29}$

Carbonisation at higher temperature $(1273 \mathrm{~K})$ and longer duration $(8 \mathrm{~h}$ and $11 \mathrm{~h})$ decomposed some $\mathrm{N}$-functional groups on the carbon surface to reduce total $\mathrm{N}$ concentrations in the CBFs to 4.6-3.9\%wt. The XPS date for CBF-1273-Ar-3h in Fig. 6b and Table 3 show that after carbonisation at $1273 \mathrm{~K}$ the nitrogen from 2-aminophenol is converted to pyridinic-N (N-4, $\mathrm{BE}=398.2 \pm 0.1 \mathrm{eV})$, pyrrolic/pyridone- $\mathrm{N}(\mathrm{N}-5, \mathrm{BE}=399.8 \pm 0.1 \mathrm{eV})$, and quaternary-N $(\mathrm{N}-6$, $\mathrm{BE}=401.1 \pm 0.1 \mathrm{eV}$ ) structures. ${ }^{30,31}$ These results are consistent with other reports on the carbonization of N-rich precursors to introduce nitrogen to carbon frameworks. ${ }^{32-34}$ For example, at temperature above $873 \mathrm{~K}$ pyridinic and pyrrolic structures are produced by decomposition of amide groups ${ }^{35}$ and the reaction of $\mathrm{NO}_{3}$ with carbon; and Chambrion et al. ${ }^{30}$ proposed C-NO reactions that lead to quaternary-N.

\subsection{Development of microporosity in the carbon foams}

$\mathrm{N}_{2}$ sorption isotherms were measured at $77 \mathrm{~K}$ on the $\mathrm{BPAC}-1023-\mathrm{CO}_{2}-1 \mathrm{~h}$ and $\mathrm{CBFs}$ and are shown in Fig. 7a. A summary of pore structure properties is provided in Table 2. The $\mathrm{N}_{2}$ sorption isotherm on BP-char was not successful, which suggests a low degree of activation and lack of pore development ${ }^{36}$. The micropore volume and D-R specific surface area of the BP-char determined from the $273 \mathrm{~K} \mathrm{CO}_{2}$ sorption isotherms were $0.14 \mathrm{~cm}^{3} \mathrm{~g}^{-1}$ and $391.1 \mathrm{~m}^{2} \mathrm{~g}^{-1}$, respectively. The activated carbon $\mathrm{BPAC}-1023-\mathrm{CO}_{2}-1 \mathrm{~h}$ produced by conventional pyrolysis and $\mathrm{CO}_{2}$ activation exhibited a Type IV isotherm ${ }^{36}$ with a hysteresis loop at relative pressures $\mathrm{P} / \mathrm{P}_{0}$ 
around 0.8 that suggests the larger mesopores are open and tubular shaped (type A hysteresis). In addition, the shape of the isotherm at lower $\mathrm{P} / \mathrm{P}_{0}$ suggests there are slit shaped pores (type $\mathrm{B}$ hysteresis) ${ }^{37}$. The pores size distribution in Fig. $7 \mathrm{~b}$ shows BPAC-1023- $\mathrm{CO}_{2}-1 \mathrm{~h}$ has a bimodal distribution of micropores around $13 \AA$ and small mesopores around $20-25 \AA$.

The $\mathrm{N}_{2}$ isotherms of the CBFs prepared under argon also feature hysteresis loops that suggest the presence of mesopores together with a degree of microporosity. As indicated by the uptake of $\mathrm{N}_{2}$ at $77 \mathrm{~K}$ (Fig. 7a) and calculated D-R micropore $\mathrm{N}_{2}$ accessible surface areas the microporosity of CBFs prepared under argon increased almost two-fold at the higher carbonization temperature, and prolonged carbonisation times produced a further increase in micropore surface area of about $15 \%$ (D-R micropore surface area). The $\mathrm{CO}_{2}$ isotherms measured at $273 \mathrm{~K}$ (Fig. 8a), and pore texture parameters in Table 2 derived from these isotherms, show consistent trends for micropore development in the CBFs as the $\mathrm{N}_{2}$ sorption analyses. The evaporation of $\mathrm{ZnO}$ particles from the carbon structure is likely to be one reason for the greater volume of micropores produced at a carbonisation temperature of $1273 \mathrm{~K}$. The CBF with the highest surface area prepared under argon (no $\mathrm{CO}_{2}$ activation) was CBF-1273-Ar-11h with a BET surface area of $190.4 \mathrm{~m}^{2} \cdot \mathrm{g}^{-1}$ and $\mathrm{CO}_{2}$ D-R micropore surface area of $628.5 \mathrm{~m}^{2} \cdot \mathrm{g}^{-1}$; however, the yield of this CBF was significantly lower than that of the CBFs prepared at $1023 \mathrm{~K}$ and short carbonisation times. The BET surface area of CBF-1273-Ar-11h is similar to that of activated carbon BPAC-1023-CO ${ }_{2}-1$ $\left(204.3 \mathrm{~m}^{2} \cdot \mathrm{g}^{-1}\right)$; but the CBFs have both larger $\mathrm{N}_{2}$-accesible pore volumes and narrow micropore volumes as measured by $\mathrm{CO}_{2}$ sorption (Table 2). Notably, the CBFs produced in this study have lower surface areas and pore volumes than the foams reported by $\mathrm{Lv}$ et al. ${ }^{1}$. A possible explanation for the difference in the results could be the ratio of furfural-aminophenol resin to BP used in the soaking experiments and this synthesis detail was not included in Lv et al.'s 
paper. To summarize, the results of our experiments with CBFs prepared in argon suggest (1) that the optimum carbonisation temperature to maximise surface area under argon is $1273 \mathrm{~K}$, and (2) carbonisation at $1273 \mathrm{~K}$ for more than $3 \mathrm{~h}$ enhances micropore development but this additional porosity is obtained with a reduced product yield. The $\mathrm{N}_{2}$ and $\mathrm{CO}_{2}$ sorption isotherms on CBF-1023-CO -3 h in Fig. 7 and Fig. 8 highlight the effectiveness of the $\mathrm{CO}_{2}$ activation step to develop microporosity compared to carbonisation of the chemically modified BP-resin composite BPC under just argon. Even at a carbonisation temperature of $1023 \mathrm{~K}$, the $\mathrm{CO}_{2}$ activated CBF has a BET area of more than $350 \mathrm{~m}^{2} \cdot \mathrm{g}^{-1}$ and twice the total pore volume as CBF1023-Ar-3h (Table 2, from the $\mathrm{N}_{2} 77 \mathrm{~K}$ isotherm). The $\mathrm{CO}_{2}$ activation process acts to widen a broad range of pore sizes - as evidenced by the increase in macropore volume by MIP (Fig. 5) and the increase in pore volume for widths from $10-40 \AA$ determined from the $\mathrm{N}_{2}$ sorption (Fig. 7b). Under $\mathrm{CO}_{2}$ activation conditions, like in the case of argon-carbonized CBFs, the surface area and micropore volumes increase with the carbonisation temperature to a maximum BET

area of $1426.1 \mathrm{~m}^{2} \cdot \mathrm{g}^{-1}$ for $\mathrm{CBF}-1273-\mathrm{CO}_{2}-1 \mathrm{~h}$. The yield of $\mathrm{CBF}-1273-\mathrm{CO}_{2}-1 \mathrm{~h}$ was $14.2 \%$ wt so by this method there is a high yield penalty to produce the highest surface area CBF. We attempted to produce a $\mathrm{CO}_{2}$ activated $\mathrm{CBF}$ at $1273 \mathrm{~K}$ treated in $\mathrm{CO}_{2}$ for 3 h (i.e. $\mathrm{CBF}-1273-\mathrm{CO}_{2}$ 3h) but this activation condition consumed almost all the carbon and there was insufficient product recovered from the furnace to characterize.

\subsection{Adsorption equilibria of pure gases}

The $\mathrm{CO}_{2}$ adsorption capacities of the CBFs and BPAC measured on the Tristar II at $273 \mathrm{~K}$ and $303 \mathrm{~K}$ and pressures up to $130 \mathrm{kPa}$ are shown in Fig. 8a andFig. 9. The carbon with the highest capacity for $\mathrm{CO}_{2}$ at these conditions was $\mathrm{CBF}-1273-\mathrm{CO}_{2}-1 \mathrm{~h}\left(5.75 \mathrm{mmol} . \mathrm{g}^{-1}\right.$ at $\left.273 \mathrm{~K}\right)$, that is the 
sample with the highest surface area and micropore volume. Compared to other carbon foams reported on literature, $\mathrm{CBFs}$ exhibited a higher capacity for $\mathrm{CO}_{2}$ per micropore surface area than some other carbon foams reported in the literature - for example at $273 \mathrm{~K}$, Tsyntsarki et al. ${ }^{39}$ reported $3.35 \mathrm{mmol} . \mathrm{g}^{-1} \mathrm{CO}_{2}$ on a pitch-derived and steam activated foam with BET of $933 \mathrm{~m}^{2} \cdot \mathrm{g}^{-1}$ and Liu et al. ${ }^{17}$ reported 2.35 mmol.g ${ }^{-1} \mathrm{CO}_{2}$ on nitrogen-doped porous carbons with a surface area of a $1148 \mathrm{~m}^{2} \cdot \mathrm{g}^{-1}$. This second example was prepared from banana peels using an aluminium nitrate synthesis procedure similar to the zinc nitrate method we used.

Fig. 10 provides a clearer picture of the effect of nitrogen functional groups and micropore surface area on $\mathrm{CO}_{2}$ uptake on the CBFs. CBP-1023-Ar-3h has the highest $\mathrm{CO}_{2}$ capture per micropore surface area, which confirms the important effect of nitrogen functional groups on the surface of the CBFs. In addition, almost linear effect of porosity development on the adsorption of $\mathrm{CO}_{2}$ is noticeable in Fig. 10b. The value of $\mathrm{CO}_{2}$ uptake divided by micropore surface area of the CBFs (Fig. 10a) is higher than almost all the biomass based activated carbons and nitrogenmodified activated carbons reported on the recent review by Rashidi and Yusup ${ }^{38} \cdot \mathrm{CO}_{2}$ adsorption analysis of the CBFs at $303 \mathrm{~K}$ (Fig. 9) showed BPAC-1023-CO $-1 \mathrm{~h}$ with the lowest micropore surface area and nitrogen contents obtained the lowest and CBF-1273- $\mathrm{CO}_{2}-1 \mathrm{~h}$ with the highest measured micropore surface area and $4.2 \%$ nitrogen content the highest $\mathrm{CO}_{2}$ capture.

Based on the high $\mathrm{CO}_{2}$ uptakes measured at low pressure, we selected $\mathrm{CBF}-1273-\mathrm{CO}_{2}-1 \mathrm{~h}$ for the high-pressure adsorption measurements. Fig. 11Error! Reference source not found.a to Fig. 13Error! Reference source not found.a present the absolute adsorption capacities for $\mathrm{CO}_{2}, \mathrm{CH}_{4}$ and $\mathrm{N}_{2}$ measured with the BelSORP apparatus CBF-1273- $\mathrm{CO}_{2}-1 \mathrm{~h}$ at temperatures of $(298,313$ and 323) $\mathrm{K}$. The high-pressure adsorption equilibria data is also included in Table S 1 of the 
Supporting Information. Compared to the $\mathrm{CO}_{2}, \mathrm{CH}_{4}$ and $\mathrm{N}_{2}$ adsorption capacities of other carbon adsorbents reported in the literature, BPAC- $1023-\mathrm{CO}_{2}-1 \mathrm{~h}$ has a reasonable capacity for these gases ${ }^{40-42}$.

The absolute adsorption capacities of $\mathrm{CO}_{2}, \mathrm{CH}_{4}$ and $\mathrm{N}_{2}$ at $298 \mathrm{~K}$ on CBF-were also measured on CBF-1273-Ar-3h (Fig. 14Error! Reference source not found. and Table S 2). As expected, the adsorption capacities on the carbon foam prepared under argon were lower than the capacities on the $\mathrm{CO}_{2}$ activated carbon foam $\mathrm{CBF}-1273-\mathrm{CO}_{2}-1 \mathrm{~h}$. The adsorption capacities for $\mathrm{CO}_{2}, \mathrm{CH}_{4}$ and $\mathrm{N}_{2}$ on $\mathrm{CBF}-1273-\mathrm{CO}_{2}-1 \mathrm{~h}$ measured at $298 \mathrm{~K}$ and $4000 \mathrm{KPa}$ were about $63 \%, 76 \%$ and $34 \%$ higher, respectively, than the capacities on CBF-1273-Ar-3h. This comparative results highlights that the $\mathrm{CO}_{2}$ activation of the foam has improved the selectivity of the $\mathrm{CBF}$ for $\mathrm{CO}_{2}$ and $\mathrm{CH}_{4}$ over $\mathrm{N}_{2}$.

A temperature-dependent, semi-empirical Toth isotherm model was tested to determine the ability of CBF-1273- $\mathrm{CO}_{2}-1 \mathrm{~h}$ to allow the prediction adsorption capacities of $\mathrm{CO}_{2}, \mathrm{CH}_{4}$ and $\mathrm{N}_{2}$ across the range of pressure and temperature conditions measured in this study. The Toth isotherm model is described by Equation $2^{43}$ :

$$
Q_{\mu i}^{\text {Toth }}=Q_{\mu i i}^{\text {Toth }} \frac{b_{i} P}{\left[1+\left(b_{i} P\right)^{t_{i}}\right]^{1 / t_{i}}} \text { with } b_{i}=b_{o, i} \exp \left(\frac{-\Delta H_{\text {Toth }, i}}{R T}\right)
$$

where $R$ is the molar gas constant, $P$ and $T$ are the measurement pressure and temperature. In the regression of this model, $\Delta H_{T o t h, i}$ was treated as an adjustable parameter together with the empirical parameters $\left(Q_{\mu i}^{\text {calc }}, b_{0, i}\right.$ or $\left.t_{i}\right)$. The parameters $t_{i}$ is used to characterise the heterogeneity of the adsorption sites in the model, but it was treated as adjustable parameter in the regression. The best fit parameters of Equation 2 were determined using a least-squares regression analysis 
to minimize the standard deviation (SD) between the measured capacities, $Q_{\mu}$, and the capacities $Q_{\mu s i}^{\text {calc }}$ calculated with the model $\left(S D=\left((1 / N) \Sigma\left(Q_{\mu i}^{\text {meas }}-Q_{\mu i}^{\text {calc }}\right)^{2}\right)^{1 / 2}\right.$ where $N$ is the number of data points regressed).

Table 4 lists the optimized parameters of Equation 2 and the standard deviations (SD) resulting from the regression of the Toth model to the $\mathrm{CBF}-1273-\mathrm{CO}_{2}-1 \mathrm{~h}$ high pressure adsorption data. Deviations $\left(Q_{\mu}^{\text {meas }}-Q_{\mu}^{\text {calc }}\right)$ between the measured and the calculated capacities of Toth model that are shown in Fig. 11Error! Reference source not found.b, Fig. 12 b and Fig. 13Error! Reference source not found.b are in the range of \pm 0.1 at most of the pressure points. This isotherm model has a SD of $0.06 \mathrm{mmol} . \mathrm{g}^{-1}$ for $\mathrm{CO}_{2}, 0.03 \mathrm{mmol} . \mathrm{g}^{-1}$ for $\mathrm{CH}_{4}$ and $0.009 \mathrm{mmol}^{-1}$ for $\mathrm{N}_{2}$.

\section{Conclusions}

Monolithic carbon foams with an open cellular structure were successfully produced from the chemically-modified banana peel precursor. The evaporation of zinc ions, which were introduced into the BP surface to form metal complexes as templates in its structure, from the carbon structure at a carbonisation temperature of $1273 \mathrm{~K}$ was showed to be one reason for the greater volume of micropores produced. The $\mathrm{CO}_{2}$ activation process was found more effective in development of micro- and macroporosity compared to the carbonisation of the chemically modified BP-resin composite BPC under just argon. After carbonisation of the precursors at $1273 \mathrm{~K}$ the nitrogen from 2-aminophenol and any naturally occurring $\mathrm{N}$ in the banana peel was converted to pyridinic-N, pyrrolic/pyridone- $\mathrm{N}$, and quaternary- $\mathrm{N}$ structures. The presence of $\mathrm{N}$ in the carbon foam produces enhanced the $\mathrm{CO}_{2}$ adsorption capacity of the carbon foams. Micropore 
development and nitrogen functionalities had positive effects on the $\mathrm{CO}_{2}$ uptake capacity of the carbon foams. The carbon foam $\mathrm{CBF}-1273-\mathrm{CO}_{2}-1 \mathrm{~h}$ with the highest $\mathrm{CO}_{2}$ and $\mathrm{CH}_{4}$ adsorption capacities and the most promising $\mathrm{CO}_{2} / \mathrm{N}_{2}$ equilibrium selectivity are comparable to adsorbents reported in literature.

\section{Acknowledgements}

This research was funded by the Australian Research Council (DE140100569, FT120100720) with additional scholarship support for Mr Arami-Niya provided through a UQ International Postgraduate Research Scholarship. We thank Dr Ge Lei for technical assistance in the laboratory, Miss Yangyang Wen for assistance with the CHNS measurements and Dr Barry Wood for assistance with XPS. We acknowledge the facilities and technical assistance of the Australian Microscopy \& Microanalysis Research facility at the Centre for Microscopy \& Microanalysis at the University of Queensland.

\section{Appendix A. Supplementary data}

Supplementary data related to this article includes: a description of the gravimetric adsorption apparatus, SEM images of dry banana peel and banan peel char, EDX spectra, and tabulated high pressure adsorption data. 


\section{References}

1. Y. Lv, L. Gan, M. Liu, W. Xiong, Z. Xu, D. Zhu and D. S. Wright, Journal of Power Sources, 2012, 209, 152-157.

2. M. Inagaki, F. Kang, M. Toyoda and H. Konno, in Advanced Materials Science and Engineering of Carbon, eds. M. Inagaki, F. Kang, M. Toyoda and H. Konno, Butterworth-Heinemann, Boston, 2014, pp. 189-214.

3. H. D. Asfaw, M. Roberts, R. Younesi and K. Edstrom, Journal of Materials Chemistry A, 2013, 1, 13750-13758.

4. C. Chen, E. B. Kennel, A. H. Stiller, P. G. Stansberry and J. W. Zondlo, Carbon, 2006, 44, 1535-1543.

5. G.-P. Hao, W.-C. Li, D. Qian, G.-H. Wang, W.-P. Zhang, T. Zhang, A.-Q. Wang, F. Schüth, H.-J. Bongard and A.-H. Lu, Journal of the American Chemical Society, 2011, 133, 11378-11388.

6. M. Inagaki, T. Morishita, A. Kuno, T. Kito, M. Hirano, T. Suwa and K. Kusakawa, Carbon, 2004, 42, 497-502.

7. R. Narasimman and K. Prabhakaran, Carbon, 2012, 50, 1999-2009.

8. Food and Agriculture Organization of the United Nations, FOASTAT, http://faostat3.fao.org/home/E.

9. T. H. Emaga, C. Robert, S. N. Ronkart, B. Wathelet and M. Paquot, Bioresource Technology, 2008, 99, 4346-4354.

10. L. Ji and G. Srzednicki, in Acta Horticulturae, 2015, pp. 541-546.

11. W. P. Clarke, P. Radnidge, T. E. Lai, P. D. Jensen and M. T. Hardin, Waste Management, 2008, 28, 527-533. 
12. H. Gupta and B. Gupta, Desalination and Water Treatment, 2016, 57, 9498-9509.

13. J. Ma, D. Huang, J. Zou, L. Li, Y. Kong and S. Komarneni, Journal of Porous Materials, 2015, 22, 301-311.

14. R. Jiang, S. Sun, Y. Xu, X. Qiu, J. Yang and X. Li, Water Science and Technology, 2015, 71, 1458-1462.

15. J. R. Memon, S. Q. Memon, M. I. Bhanger, A. El-Turki, K. R. Hallam and G. C. Allen, Colloids and Surfaces B: Biointerfaces, 2009, 70, 232-237.

16. M. Thirumavalavan, Y.-L. Lai, L.-C. Lin and J.-F. Lee, Journal of Chemical \& Engineering Data, 2009, 55, 1186-1192.

17. R.-L. Liu, W.-J. Ji, T. He, Z.-Q. Zhang, J. Zhang and F.-Q. Dang, Carbon, 2014, 76, 8495.

18. E. M. Lotfabad, J. Ding, K. Cui, A. Kohandehghan, W. P. Kalisvaart, M. Hazelton and D. Mitlin, ACS Nano, 2014, 8, 7115-7129.

19. A. Arami-Niya, T. E. Rufford and Z. Zhu, Carbon, 2016, 103, 115-124.

20. P. S. Patel and S. R. Patel, European Polymer Journal, 1987, 23, 733-735.

21. B. Liu, H. Shioyama, T. Akita and Q. Xu, Journal of the American Chemical Society, 2008, 130, 5390-5391.

22. B. Liu, H. Shioyama, H. Jiang, X. Zhang and Q. Xu, Carbon, 2010, 48, 456-463.

23. R. Kumar, S. R. Dhakate, T. Gupta, P. Saini, B. P. Singh and R. B. Mathur, Journal of Materials Chemistry A, 2013, 1, 5727-5735.

24. M. Inagaki, J. Qiu and Q. Guo, Carbon, 2015, 87, 128-152.

25. T. Beechem, K. Lafdi and A. Elgafy, Carbon, 2005, 43, 1055-1064. 
26. N. Graf, E. Yegen, T. Gross, A. Lippitz, W. Weigel, S. Krakert, A. Terfort and W. E. S. Unger, Surface Science, 2009, 603, 2849-2860.

27. R. J. J. Jansen and H. van Bekkum, Carbon, 1995, 33, 1021-1027.

28. J. R. Pels, F. Kapteijn, J. A. Moulijn, Q. Zhu and K. M. Thomas, Carbon, 1995, 33, 1641-1653.

29. A. Krepelova, J. Newberg, T. Huthwelker, H. Bluhm and M. Ammann, Physical Chemistry Chemical Physics, 2010, 12, 8870-8880.

30. P. Chambrion, T. Suzuki, Z.-G. Zhang, T. Kyotani and A. Tomita, Energy \& Fuels, 1997, 11, 681-685.

31. H. Chen, G. Lin, Y. Chen, W. Chen and H. Yang, Energy \& Fuels, 2015.

32. G.-P. Hao, W.-C. Li, D. Qian and A.-H. Lu, Advanced Materials, 2010, 22, 853-857.

33. J. P. McGann, M. Zhong, E. K. Kim, S. Natesakhawat, M. Jaroniec, J. F. Whitacre, K. Matyjaszewski and T. Kowalewski, Macromolecular Chemistry and Physics, 2012, 213, 1078-1090.

34. D. Hulicova-Jurcakova, M. Kodama, S. Shiraishi, H. Hatori, Z. H. Zhu and G. Q. Lu, Advanced Functional Materials, 2009, 19, 1800-1809.

35. R. J. J. Jansen and H. van Bekkum, Carbon, 1994, 32, 1507-1516.

36. H. Marsh and F. Rodríguez-Reinoso, in Activated Carbon, eds. H. Marsh and F. Rodríguez-Reinoso, Elsevier Science Ltd, Oxford, 2006, pp. 143-242.

37. D. D. Duong, in Adsorption Analysis: Equilibria and Kinetics, Imperial College Press, 1998, pp. 49-148.

38. N. A. Rashidi and S. Yusup, Journal of CO2 Utilization, 2016, 13, 1-16. 
39. B. Tsyntsarski, B. Petrova, T. Budinova, N. Petrov, L. F. Velasco, J. B. Parra and C. O. Ania, Microporous and Mesoporous Materials, 2012, 154, 56-61.

40. S. García, J. J. Pis, F. Rubiera and C. Pevida, Langmuir, 2013, 29, 6042-6052.

41. F. Dreisbach, R. Staudt and J. U. Keller, Adsorption, 1999, 5, 215-227.

42. T. E. Rufford, G. C. Y. Watson, T. L. Saleman, P. S. Hofman, N. K. Jensen and E. F. May, Industrial \& Engineering Chemistry Research, 2013, 52, 14270-14281.

43. J. Toth, Acta Chim. Acad. Sci. Hung., 1971, 69, 311-328. 


\section{Figure captions}

Fig. 1 Process block flow diagram of (a) zinc complex templated furfural +2 -aminophenol procedures to produce activated carbons and (b) pyrolysis to char, and then physical activation with $\mathrm{CO}_{2}$.

Fig. 2 SEM images of dry peel from Cavendish bananas (BP).

Fig. 3 Thermal gravimetric analysis of dried banana peel (BP) and banana peel-zinc composite impregnated with furfural and 2-aminophenol (BPC) in $20 \mathrm{~mL} / \mathrm{min} \mathrm{N} 2$, heating rate $10 \mathrm{~K} / \mathrm{min}$. Weight $\%$ is on a dry basis after removal of adsorbed moisture and any other light gases at temperature below to $473 \mathrm{~K}$.

Fig. 4 SEM images of soft templated carbon foams (a-c) BPC-1273-Ar-3h, prepared at $1273 \mathrm{~K}$ under argon for 3 hours and (d-f) BPC- $1273-\mathrm{CO}_{2}-1 \mathrm{~h}$, prepared at $1273 \mathrm{~K}$ under $\mathrm{CO}_{2}$ for $1 \mathrm{~h}$, and (g-i) example of a $\mathrm{CO}_{2}$ activated banana peel carbon ACBP-1023- $\mathrm{CO}_{2}-1 \mathrm{~h}$.

Fig. 5 Differential pore volumes versus pore diameter obtained from mercury intrusion porosimetry for BPC-1273-Ar-3h and BPC-1273-CO $\mathrm{CO}_{2}-1 \mathrm{~h}$.

Fig. 6 XPS spectrum of BPC, BPC-1273-Ar-3h and BPC-1273- $\mathrm{CO}_{2}-1 \mathrm{~h}$ and high-resolution fitted XPS spectra of $\mathrm{N} 1 \mathrm{~s}$ peak for these samples.

Fig. 7 (a) $\mathrm{N}_{2}$ adsorption-desorption isotherm measured at $77 \mathrm{~K}$ on on $\mathrm{CO}_{2}$ activated banana peel carbon ACBP-1023- $\mathrm{CO}_{2}-1$. And the zinc-complex furfural + 2-aminophenol derived banana peel carbons (BPCs). (b) Pore size distribution determined from isotherms measured at $77 \mathrm{~K}$ with $\mathrm{N}_{2}$.

Fig. 8 (a) $\mathrm{CO}_{2}$ adsorption capacities at $273 \mathrm{~K}$ for banana peel derived zinc-complex templated carbon foams and activated carbons measured at pressures up to $130 \mathrm{kPa}$ on the Micromeritics Tristar II (b) Pore size distribution determined from isotherms measured at $273 \mathrm{~K}$ with $\mathrm{CO}_{2}$.

Fig. $9 \mathrm{CO}_{2}$ adsorption capacities at $303 \mathrm{~K}$ for chemically-modified banana foams and activated carbons measured at pressures up to $130 \mathrm{kPa}$ on the Micromeritics Tristar II.

Fig. 10 Relationship between the $\mathrm{CO}_{2}$ uptake capacity and (a) nitrogen content, (b) micropore surface area.

Fig. 11 Measured and modelled $\mathrm{CO}_{2}$ adsorption capacities for soft templated carbon foam BPC$1273-\mathrm{CO}_{2}-1 \mathrm{~h}$ at temperatures of $298 \mathrm{~K}, 313 \mathrm{~K}$ and $323 \mathrm{~K}$. (a) Absolute adsorption capacities. The lines represent the predictions of the Toth model (Eq. 4). (b) Deviations between the measured and the calculated adsorption capacities. 
Fig. 12 Measured and modelled $\mathrm{CH}_{4}$ adsorption capacities for soft templated carbon foam BPC$1273-\mathrm{CO}_{2}-1 \mathrm{~h}$ at temperatures of $298 \mathrm{~K}, 313 \mathrm{~K}$ and $323 \mathrm{~K}$. (a) Absolute adsorption capacities. The lines represent the predictions of the Toth model (Eq. 4). (b) Deviations between the measured and the calculated adsorption capacities.

Fig. 13 Measured and modelled $\mathrm{N}_{2}$ adsorption capacities for soft templated carbon foam BPC$1273-\mathrm{CO}_{2}-1 \mathrm{~h}$ at temperatures of $298 \mathrm{~K}, 313 \mathrm{~K}$ and $323 \mathrm{~K}$. (a) Absolute adsorption capacities. The lines represent the predictions of the Toth model (Eq. 4). (b) Deviations between the measured and the calculated adsorption capacities.

Fig. $14 \mathrm{CO}_{2}, \mathrm{CH}_{4}$ and $\mathrm{N}_{2}$ absolute adsorption capacities at $298 \mathrm{~K}$ on BPC-1273-Ar-3h measured on the Belsorb-BG. 
Table 1 Carbon product yield, proximate analysis by ASTM D 7582-10 using TGA and elemental composition measured by CHNS/O analyser.

\begin{tabular}{|c|c|c|c|c|c|c|c|c|}
\hline \multirow[b]{2}{*}{ Sample } & \multirow[b]{2}{*}{ Description of carbon form } & \multirow[b]{2}{*}{ Yield $(\%)$} & \multicolumn{3}{|c|}{ ASTM D 7582-10 } & \multicolumn{3}{|c|}{ Elemental Composition (\%) } \\
\hline & & & $\begin{array}{c}\text { Fixed } \\
\text { carbon } \\
(\% \mathrm{wt})\end{array}$ & $\begin{array}{c}\text { Volatiles } \\
\text { (\%wt.) }\end{array}$ & $\begin{array}{l}\text { Ash } \\
(\% \mathrm{wt})\end{array}$ & $\mathrm{N}$ & $\mathrm{C}$ & $\mathrm{H}$ \\
\hline BP-Raw & - & - & 24.2 & 67.7 & 8.2 & 1.9 & 42.0 & 5.6 \\
\hline BP-char & Agglomerated carbon particles & 38.8 & 65.8 & 21.6 & 12.7 & 2.1 & 48.8 & 1.1 \\
\hline BPC & - & - & 40.8 & 45.9 & 13.3 & 8.0 & 32.4 & 3.6 \\
\hline BPC-1023-Ar-3h & Monolith carbon & 65.7 & 66.1 & 22.3 & 11.6 & 6.0 & 47.5 & 0.7 \\
\hline BPC-1273-Ar-3h & Monolith carbon & 30.1 & 84.7 & 10.7 & 4.6 & 4.6 & 70.0 & 1.3 \\
\hline BPC-1273-Ar-8h & Monolith carbon & 26.4 & 82.3 & 12.2 & 5.4 & 4.5 & 70.4 & 1.2 \\
\hline BPC-1273-Ar-11h & Monolith carbon & 23.6 & 85.6 & 10.5 & 3.9 & 3.9 & 70.4 & 1.0 \\
\hline BPC-1023-CO $2-3 \mathrm{~h}$ & Monolith carbon & 45.2 & 55.8 & 32.3 & 11.9 & 3.9 & 27.4 & 1.1 \\
\hline $\mathrm{BPC}-1123-\mathrm{CO}_{2}-3 \mathrm{~h}$ & Monolith carbon & 24.6 & 44.4 & 31.9 & 23.7 & 4.0 & 30.2 & 1.4 \\
\hline BPC-1273- $-\mathrm{CO}_{2}-1 \mathrm{~h}$ & Monolith carbon & 14.2 & 76.3 & 16.2 & 7.5 & 4.2 & 43.5 & 2.2 \\
\hline BPAC-1023-CO ${ }_{2}-1 \mathrm{~h}$ & Agglomerated carbon particles & 67.9 & 60.1 & 28.6 & 11.3 & 2.3 & 33.8 & 1.5 \\
\hline
\end{tabular}


Table 2 Surface textural properties of zinc complex templated carbon foams from banana peel $(\mathrm{CBF})$, $\mathrm{BP}$-char and a $\mathrm{CO}_{2}$ activated banana peel carbon (BPAC-1023-CO $\mathrm{CO}_{2}-1 \mathrm{~h}$ ) determined from sorption isotherms of $\mathrm{N}_{2}$ at $77 \mathrm{~K}_{\text {and }} \mathrm{CO}_{2}$ at $273 \mathrm{~K}$.

\begin{tabular}{|c|c|c|c|c|c|c|}
\hline \multirow[b]{2}{*}{ Sample } & \multicolumn{4}{|c|}{$\mathrm{N}_{2}$} & \multicolumn{2}{|c|}{$\mathrm{CO}_{2}$} \\
\hline & $\begin{array}{c}\text { D-A Micropore } \\
\text { Surface area } \\
\left(\mathrm{m}^{2} \cdot \mathrm{g}^{-1}\right)\end{array}$ & $\begin{array}{l}\text { Micropore } \\
\text { Volume } \\
\left(\mathrm{cm}^{3} \cdot \mathrm{g}^{-1}\right) \\
\end{array}$ & $\begin{array}{c}\text { BET surface } \\
\text { area } \\
\left(\mathrm{m}^{2} \cdot \mathrm{g}^{-1}\right) \\
\end{array}$ & $\begin{array}{l}\text { Pore volume } \\
\left(\mathrm{cm}^{3} \cdot \mathrm{g}^{-1}\right)\end{array}$ & $\begin{array}{c}\text { D-R Micropore } \\
\text { Surface area } \\
\left(\mathrm{m}^{2} \cdot \mathrm{g}^{-1}\right)\end{array}$ & $\begin{array}{c}\text { Micropore } \\
\text { Volume } \\
\left(\mathrm{cm}^{3} \cdot \mathrm{g}^{-1}\right) \\
\end{array}$ \\
\hline BP-char & - & - & - & - & 391.1 & 0.14 \\
\hline BPC-1023-Ar-3h & 102.7 & 0.04 & 91.5 & 0.093 & 337 & 0.14 \\
\hline BPC-1273-Ar-3h & 198.3 & 0.07 & 169 & 0.18 & 620.9 & 0.29 \\
\hline BPC-1273-Ar-8h & 225.7 & 0.08 & 183.6 & 0.19 & 675.5 & 0.31 \\
\hline BPC-1273-Ar-11h & 228.7 & 0.08 & 190.4 & 0.17 & 628.5 & 0.3 \\
\hline $\mathrm{BPC}-1023-\mathrm{CO}_{2}-3 \mathrm{~h}$ & 446.7 & 0.16 & 352.2 & 0.22 & 369.3 & 0.23 \\
\hline BPC-1123- $\mathrm{CO}_{2}-3 \mathrm{~h}$ & 644.7 & 0.26 & 533.6 & 0.31 & 365.3 & 0.35 \\
\hline $\mathrm{BPC}-1273-\mathrm{CO}_{2}-1 \mathrm{~h}$ & 1611 & 0.56 & 1426.1 & 0.83 & 881.93 & 1.09 \\
\hline BPAC-1023- $\mathrm{CO}_{2}-1 \mathrm{~h}$ & 234.1 & 0.11 & 204.3 & 0.11 & 299.9 & 0.27 \\
\hline
\end{tabular}


Table 3 Nitrogen contents, peak analysis and type of nitrogen groups on the BPC and carbon foam surfaces determined using XPS; N-1: primary amine groups, N-2: amide groups, N-3: nitrates, N-4: pyridine, N-5: pyrrol or other forms of pyridine like nitrogens, N-6: quaternary nitrogen.

\begin{tabular}{|c|c|c|c|c|c|c|c|c|}
\hline \multirow[b]{3}{*}{ Sample } & \multirow{3}{*}{$\begin{array}{c}\text { Overall N } \\
\text { content (\%) }\end{array}$} & \multirow{3}{*}{$\begin{array}{c}\text { Overall } O \\
\text { content (\%) }\end{array}$} & $\mathrm{N}-1(\%)$ & $\mathrm{N}-2(\%)$ & $\mathrm{N}-\mathbf{3}(\%)$ & $\mathrm{N}-4(\%)$ & $\mathrm{N}-5(\%)$ & $\mathrm{N}-6(\%)$ \\
\hline & & & $399.4 \pm 0.1 \mathrm{eV}$ & $400.5 \pm 0.1 \mathrm{eV}$ & $407.3 \pm 0.1 \mathrm{eV}$ & $398.2 \pm 0.1 \mathrm{eV}$ & $399.8 \pm 0.1 \mathrm{eV}$ & $401.1 \pm 0.1 \mathrm{eV}$ \\
\hline & & & \multicolumn{6}{|c|}{ Schematic } \\
\hline $\mathrm{BPC}$ & 20.6 & 6.9 & 36.9 & 21.6 & 41.5 & - & - & - \\
\hline BPC-1273-Ar-3h & 7.5 & 4.6 & - & - & - & 37.8 & 17.9 & 44.3 \\
\hline BPC-1273- $\mathrm{CO}_{2}-1 \mathrm{~h}$ & 10 & 4.9 & - & - & - & 38.7 & 37.2 & 24.1 \\
\hline
\end{tabular}


Table 4 Fitting parameters of the Toth Model for $\mathrm{CO}_{2}, \mathrm{CH}_{4}$ and $\mathrm{N}_{2}$ on $\mathrm{CBF}-1273-\mathrm{CO}_{2}-1 \mathrm{~h}$

\begin{tabular}{|c|c|c|c|c|c|}
\hline \multirow[b]{2}{*}{ Gas } & \multicolumn{5}{|c|}{ Toth model } \\
\hline & $\begin{array}{c}Q_{\max , i} \\
\left(\mathrm{mmol} \cdot \mathrm{g}^{-1}\right)\end{array}$ & $b_{0, i \bullet} 10^{6}(M P a)$ & $\begin{array}{c}-\Delta H_{T o t h, i} \\
\left(J \cdot \mathrm{mmol}^{-1}\right)\end{array}$ & $t_{i}$ & $S D\left(\mathrm{mmol} \cdot \mathrm{g}^{-1}\right)$ \\
\hline $\mathrm{CO}_{2}$ & 24.7 & 0.22 & 30 & 0.26 & 0.21 \\
\hline $\mathrm{CH}_{4}$ & 7.65 & 0.64 & 20.3 & 0.61 & 0.04 \\
\hline $\mathrm{N}_{2}$ & 5.75 & 1.24 & 15.7 & 0.71 & 0.009 \\
\hline
\end{tabular}




\section{Supporting Information captions}

Fig. S1 SEM images of (a-c) the dry banana peel precursor (BP) and (d-f) banana peel derived char (BP-char) pyrolysed at $873 \mathrm{~K}$ for 1 hour.

Fig. S2 EDX analysis of (a) BPC- (b) BPC-1023-Ar-3h (c) BPC-1273-Ar-3h.

Table $\mathbf{S} 1$ Measured absolute adsorption capacities for $\mathrm{CO}_{2}, \mathrm{CH}_{4}$, and $\mathrm{N}_{2}$ on BPC-1273- $\mathrm{CO}_{2}-1 \mathrm{~h}$ at $298 \mathrm{~K}, 313 \mathrm{~K}$ and $323 \mathrm{~K}$, and the corresponding uncertainty $u\left(Q_{a b s}\right)$.

Table S 2 Measured absolute adsorption capacities for $\mathrm{CO}_{2}, \mathrm{CH}_{4}$, and $\mathrm{N}_{2}$ on BPC-1273-Ar-3h at 298 K measured with the Belsorb-BG. 